\title{
Alfonso VI y el monasterio de Sahagún. Nuevos testimonios sobre la construcción del templo mo- nástico ${ }^{1}$
}

\author{
C. Cosmen Alonso - M. V. Herráez Ortega - M. Valdés Fernández \\ Universidad de León
}

“...set super omnes, ecclesiam Sanctorum Facundi et Primitivi, quem antiquitus Dompnis Sanctus vocitant, amavi”

(Alfonso VI, Fueros de Sahagún, 1085)

RESUMEN.. El monasterio de Sahagún vivió su etapa más brillante a finales del siglo XI y comienzos de la centuria siguiente, periodo en el que se encontraba bajo la protección de Alfonso VI. La parcial limpieza llevada a cabo en las ruinas del templo permite constatar la existencia de una cabecera levantada en época alfonsí, cuyas formas artísticas y las marcas de cantero utilizadas contrastan con las del transepto, construido en la segunda mitad del siglo XII.

Palabras clave: Edad Media, Alfonso VI, arte románico, arquitectura, monasterio de Sahagún, marcas de cantero.

ABSTRACT. Monastery of Sahagún lived its most brilliant period at the end of $11^{\text {th }}$ Century and the beginning of the next one, when it was under the protection of Alfonso VI. As the ruins have been parcially cleaned, we can confirm that the apses of the abacial churh were built at the end of the $11^{\text {th }}$ Century; the arqueology of architecture and the masons' marks are diferent from those of the crossing, which dates from the second half of the $12^{\text {th }}$ Century.

Key Words: Middle Ages, Alfonso VI, Romanic art, architecture, monastery of Sahagún, masons' marks.

El monasterio de San Benito de Sahagún fue uno de los centros más destacados de la Edad Media hispana y por ello ha sido objeto de numerosos estudios que abarcan periodos $\mathrm{y}$ aspectos diferentes. En el año 2000 vio la luz el libro titulado Esplendor y decadencia de un monasterio medieval. El patrimonio artístico de San Benito de Sahagún, fruto de un trabajo de investigación que permitió hacer la recomposición artística de las distintas fases de construcción del monasterio y poner de relieve la complejidad de un recinto sometido a fluctuaciones litúrgicas, cultuales, políticas, económicas y

${ }^{1}$ Este trabajo se ha desarrollado dentro del proyecto de
I+D con referencia HUM2004-04387, financiado por el Ministerio de Educación y Ciencia. sociales, ligadas al devenir histórico y a los avatares de la propia villa de Sahagún ${ }^{2}$.

\section{-}

2 M. V. HERrÁEz ORTEGA (COORD.), Esplendor y decadencia de un monasterio medieval. El patrimonio artístico de San Benito de Sahagún, León, 2000. En esta publicación se encuentran relacionadas las principales fuentes y bibliografía sobre el monasterio, por lo que obviamos su repetición. Con posterioridad al año 2000, han aparecido nuevos trabajos que abordan aspectos artísticos puntuales del periodo medieval: J. SENRA GABRIEL y GALÁN, "Una olvidada Maiestas Domini procedente del monasterio benedictino de Sahagún (León)", en R. SÁNCHEZ AMEIJEIRAS y J. L. SENRA GABRIEL Y GALÁN (coords.), El Tímpano románico: imágenes, estructuras y audiencias, Santiago de Compostela, 2003, pp. 209-229; J. PÉREZ GIL Y J. J. SÁNCHEZ BADIOLA, Monarquía y monacato en la Edad Media peninsular, León, 2002, y J. L. SENRA GABRIEL y GALÁN, “Ángeles en Castilla: reflexiones en torno a renovación monástica y arquitectura en el siglo XI", en Patrimonio artístico de Galicia y otros estudios. Homenaje al Profesor Dr. Serafin 
Casi al mismo tiempo que esa publicación veía la luz, se realizaron trabajos de limpieza, consolidación y protección de algunas estructuras arquitectónicas. En concreto, en el espacio correspondiente al ábside Norte de la cabecera románica se rebajó el nivel del suelo permitiendo que aparecieran los zócalos de los muros, aspecto que anteriormente era imposible vislumbrar. El estudio de estos nuevos elementos, unido al análisis de las marcas de cantería, permite ahora profundizar en la contextualización de esta parte del templo y confirmar la hipótesis, expuesta en el libro anteriormente citado, de que los restos conservados de la cabecera del templo formaban parte de la obra llevada a cabo en el monasterio bajo la protección de Alfonso VI.

La primera fundación altomedieval giraba en torno a un templo o "cella memoriae" en donde se veneraban las reliquias de los santos mártires Facundo y Primitivo, encontradas junto al Cea. Ese edificio fue sustituido por otros más acordes al contexto cultual, artístico y litúrgico de los siglos VIII, IX y X, de los que apenas quedan más que el recuerdo literario y escasas referencias documentales. Las estructuras prerrománicas empezaron a quedar obsoletas a finales del siglo XI, cuando la abadía se convirtió en foco de la reforma cluniacense y en mausoleo de su más insigne valedor, Alfonso VI.

Las relaciones exteriores, favorecidas por su posición de enclave privilegiado del Camino de Santiago, se intensificaron a través de diferentes vías. Por un lado, los contactos con Cluny, iniciados ya en época de Fernando I, se vieron reforzados al llegar a Sahagún, en 1080, el monje Bernardo de la Sauvetat con el nombramiento de abad y la encomienda de implantar en la liturgia el rito romano; por otra parte, ese mismo hecho permitió estrechar los lazos con el papado, del que el monasterio dependía directamente, y, por último, el matrimonio del rey con Constanza de Borgoña, hubo de facilitar el intercambio cultural con el territorio transpirenaico. Testimonios materiales de esa apertura hacia Europa son la utilización de la letra carolina en el scriptorium monástico en fechas tem-

Moralejo Álvarez, t. III, Santiago de Compostela, 2004, pp. 261-274. pranas o la iconografía de la lauda sepulcral de Alfonso Ansúrez (1093) ${ }^{3}$.

No es extraño que, en ese contexto, se intentaran actualizar las estructuras arquitectónicas de acuerdo a los modelos del románico europeo que ya se imponían en el Norte peninsular, especialmente en los focos más destacados del Camino de Santiago ${ }^{4}$.

Alfonso VI había manifestado en varias ocasiones su predilección por el monasterio de San Facundo, en torno al cual crecía una villa dotada de fueros desde 1085 en donde la monarquía, y a su sombra la nobleza, construía palacios en los que se instalaba largas temporadas. En 1080 el rey ya había tomado la decisión de recibir en él sepultura:

"Elegí allí el lugar donde descansar tras mi muerte, de manera que lo que había amado extremadamente en vida. yo difunto, también fuese a más,

Las razones de esa elección quedan patentes en la expresión utilizada por el propio monarca: era un lugar por el que sentía especial devoción $\mathrm{y}$, además, tenía clara conciencia del prestigio que ello suponía para el cenobio, motivos ambos que quedan menos explícitos en otros muchos casos pero que sabemos movieron a altos personajes, laicos y eclesiásticos, especialmente a lo largo de la Baja Edad Media, a

\section{-}

${ }^{3}$ El primer documento redactado en el escriptorium monástico en escritura carolina data de 1104 . Vid. J. A. FERNÁNDEZ FLÓREZ, Colección diplomática del monasterio de Sahagún (857-1230), t. IV (110-1199), León, 1991, p. XXXII). La iconografía de la lauda de Alfonso Ansúrez fue estudiada por S. MORALEJO, "The tomb of Alfonso Ansúrez $(+1093)$; its place and the role of Sahagún in the beginnings of Spanish Romanesque Sculpture", Santiago, Saint-Denis and Saint Peter, the reception of the Roman Liturgy in León-Castilla in 1080, New York, 1985, pp. 63-100, trabajo que fue traducido en "La lauda sepulcral de Alfonso Ansúrez (+1093): su lugar en el desarrollo de la escultura románica hispana y su relación con el arte jaqués", en Patrimonio artístico de Galicia y otros estudios, t. I, Santiago de Compostela, 2004, pp. 131-139. Puede consultarse también D. HASSIG, "He will make alive your mortal bodies: cluniac spirituality and the Tomb of Alfonso Ansúrez", Gesta, XXX/2, 1991, pp. 140-153.

${ }^{4}$ Sobre la renovación arquitectónica monástica y la reforma litúrgica en este momento en el Noroeste peninsular puede consultarse el reciente trabajo de J. L. SENRA GABRIEL Y GALÁN, "Ángeles en Castilla: reflexiones...", pp. 261-174.

5 M. HerRero DE LA FUENTE, Colección diplomática del monasterio de Sahagún (857-1230), t. III, León, 1988, doc. 786. 
fundar lugares de enterramiento vinculados a distintas instituciones religiosas. De este modo, el monasterio de Sahagún fue dotado, en las últimas décadas del siglo XI, con un espacio funerario situado a los pies del templo prerrománico ${ }^{6}$. Con ello el rey no hacía sino continuar con una tradición hispana cuyo testimonio más próximo era el Panteón de su padre, Fernando I, en San Isidoro de León ${ }^{7}$.

Una vez terminadas las obras del recinto en el que reposaría el cuerpo de Alfonso VI, probablemente en relación con ese deseo regio de engrandecer la abadía, se decidió sustituir la basílica que había fundado Alfonso III por una iglesia románica, más adaptada a la nueva liturgia romana. Bernardo de la Sauvetat fue nombrado arzobispo de la metropolitana de Toledo en 1085 , cuando aún no se habían iniciado los

-

6 J. PÉREZ GIL Y J. J. SÁNCHEZ BADIOLA, Monarquía y monacato en la Edad Media peninsular, León, 2002, pp. 57 y ss., 161 y 165 , se muestran reticentes a aceptar que se trate de una obra de finales del siglo XI y no de una parte del templo prerrománico remozado a finales del siglo XII o comienzos del XIII, según la teoría defendida por los monjes historiadores y por la historiografía anterior al trabajo de J. L. SENRA GABRIEL y GALÁN, "Aproximación a los espacios litúrgico-funerarios en Castilla y León: pórticos y galileas", Gesta, vol. XXXVI/2, 1997, pp. 122-144, esp. $128-130$, y al nuestro ya citado. No es objetivo de este estudio la construcción del Panteón; sin embargo, nos reafirmamos en que razones de carácter estilístico, litúrgico y cultual en relación con las reliquias que en él se veneraban -la mayoría de ellas ya expuestas en el libro al que hemos hecho referencia-, así como la propia evolución de los espacios monásticos y de sus advocaciones, además de la necesidad de un lugar apropiado para que reposaran los restos mortales de Alfonso VI, indican que a finales del siglo XI hubo de construirse la que, posteriormente, se denominaría capilla de san Mancio. Si para ello se reaprovechó parte de los muros de la iglesia de Alfonso III, es algo que solo un informe sobre la excavación efectuada en 1932, hasta hoy desconocido, o una nueva prospección arqueológica podrían desentrañar, pero ello hubiera supuesto una gran disminución del espacio litúrgico del templo en un momento en que el monasterio estaba en plena expansión y, en cualquier caso, el decoro hubiera exigido una adaptación a la arquitectura del momento. En el siglo XII se abriría la puerta occidental para facilitar el acceso directo desde el exterior y a comienzos del XIII, se ampliaría el vano original de comunicación con la iglesia. Ambas obras, según las fotografías conservadas, responderían a una estética propia del románico avanzado, lo que ha podido inducir a alguna confusión historiográfica sobre el conjunto del panteón.

${ }^{7}$ Entre las últimas publicaciones sobre el Panteón de Fernando I, cabe destacar M. VALDÉS FERnÁNDEZ, "El panteón Real de la Colegiata de San Isidoro", en Maravillas de la España medieval. Tesoro sagrado y monarquía, Madrid, 2001, pp. 73-84, y A. GARCÍA MARTínEZ, "Aproximación crítica a la historiografía de San Isidoro de León”, Estudios Humanísticos. Historia, IV, 2005, pp. 5393. trabajos. Hubo de ser el abad Diego (10871110) quien, según rezaba su desaparecido epitafio, puso los cimientos del nuevo templo ${ }^{8}$. La consagración tuvo lugar en el año 1099, con la asistencia del arzobispo Bernardo, obispos, abades, nobles y caballeros ${ }^{9}$. Por esas fechas estarían levantados los tres ábsides semicirculares que conformaban la cabecera y permitían la colocación de altares para la celebración litúrgica. En 1106 se alaba la fábrica de la iglesia, "ecclesia mira opera fabricata"10, que llamaría la atención no sólo por su labra sino también por sus dimensiones.

A la muerte del rey $(+1109)$, los desórdenes acaecidos en la villa dificultaron la continuación de las obras, de modo que el transepto y las naves se construyeron ya a partir de mediados del siglo XII y aún en el XIII, con una lentitud justificada por el levantamiento reiterado de los burgueses contra la tiranía del abad y por el alejamiento de la Corte hacia el Sur. El claustro y las dependencias conventuales también se fueron renovando o se ampliaron conforme a las necesidades de la vida regular, los usos funerarios y la hospitalidad propia de los grandes cenobios del Camino de Santiago ${ }^{11}$.

Las intervenciones continuaron a lo largo de las centurias siguientes, unas veces como acción reparadora de lo que el tiempo y los propios hombres deterioraban $\mathrm{y}$, otras, como resultado de la sustitución de estructuras que quedaban anticuadas para los distintos usos y estética de cada momento. La mudanza y renovación de las formas es una condición inherente a todos los edificios "vivos", como organismos que cumplen unas funciones determinadas y han de adaptarse a los tiempos. Pero, además, la abadía sahagunina presenta un caso singular de patrimonio histórico-artístico ya que no signifi-

8 "Opera ecclesiae fundamentum primus posuit". Cifr. GuARDIOLA, Historia del monasterio de San Benito el Real de Sahagún, ms. 1519 de la Biblioteca Nacional, fols. 290v.291r; J. M. QUADRADO Y F. J. PARCERISA, Recuerdos y bellezas de España. Asturias y León, Barcelona, 1855, p. 155.

${ }^{9}$ Fr. R. EsCALONA, Historia del Real Monasterio de Sahagún, sacada de la que dexo escrita el P. Maestro Fray Josef Pérez, Madrid, 1782, p. 300.

10 M. HeRrero DE LA Fuente, Colección diplomática..., t. III, León, 1988, doc. 1133.

${ }^{11}$ Sobre las modificaciones y ampliaciones llevadas a cabo a partir del siglo XIII remitimos a de M. V. HERRÁEZ Y M. D. TEIJEIRA, "Los siglos del gótico", en Esplendor y decadencia de un monasterio medieval..., pp. 135 y ss. 
có un elemento de identidad para la sociedad del entorno; bien al contrario, los burgueses de la villa vieron en ella un símbolo de opresión y rivalidad contra el que lucharon denodadamente desde comienzos del siglo XII. Su historia, por lo tanto, es una sucesión y superposición de actos creadores y devastadores que culminaron con la ocupación del recinto por las tropas durante la Invasión Francesa.

El proceso de destrucción al que fue sometido el monasterio por parte de la soldadesca y las nuevas necesidades monásticas, condujeron a la elaboración de un proyecto de iglesia decimonónica que respetaba en parte la estructura y el espacio anterior, pero implicaba un cambio sustancial: la modificación de la orientación del templo, con la construcción de una gran portada neoclásica abierta hacia el burgo, en el lugar que ocupaba el ábside central, y sendas torres sobre los laterales, de las que únicamente llegó a levantarse la del lado Norte ${ }^{12}$. El programa ideado por el arquitecto de la Congregación benedictina de Valladolid, el padre Miguel Echano, no pudo concluirse antes de la entrada en vigor del Decreto de Desamortización; sin embargo, el inicio de las obras supuso el trazado de un muro recto en el extremo oriental del templo que cercenó los ábsides y provocó la desaparición de una parte de las estructuras románicas que aún se mantenían en pie. A partir de 1835, el incendio provocado por los liberales y la pérdida de la función conventual debida al decreto de Álvarez de Mendizábal, supusieron un progresivo deterioro del edificio y el abandono definitivo por parte del Estado $^{13}$.

En 1931 las ruinas del monasterio de san Facundo fueron declaradas monumento histórico-artístico ${ }^{14}$. Ello no impidió el trazado de una carretera y la construcción de una Casa-cuartel

-

12 El proyecto de reforma y las obras llevadas a cabo en la iglesia entre 1819 y 1934 han sido ampliamente tratados por E. ZARAGOZA PASCUAL, "Planos y reedificación de la iglesia del monasterio de San Benito de Sahagún (18241831)", Archivos leoneses, $\mathrm{n}^{\circ} 82-84,1988$, pp. 363-385, y M. D. CAMPOS, "El malogrado intento de restauración en el siglo XIX”, en M. V. HERRÁEZ (COORD.), Esplendor y decadencia..., pp. 227-237.

${ }^{13}$ La Orden de Supresión del monasterio data de 21 de septiembre de 1835. J. M. CUENCA COLOMA, Sahagún. Monasterio y villa (1085-1985), Valladolid, 1993, pp. 382383.

${ }^{14}$ Decreto 0265M de 3 de junio de 1931. de la Guardia Civil sobre el solar de la iglesia, lo que acabó enterrando su recuerdo.

Por tanto, de lo que en su día fue un complejo monástico rico y floreciente, uno de los centros más poderosos de la España medieval, sólo quedan hoy a la vista fragmentos arruinados de la estructura templaria y de alguna dependencia aneja, enmascarados entre fábricas deleznables de los siglos XIX y XX, que contrastan con la grandeza de los muros románicos.

Con la aportación que supone este trabajo, además de profundizar en el conocimiento del arte románico del periodo alfonsí, esperamos contribuir a las necesarias tareas de excavación, conservación y puesta en valor de los vestigios del templo monástico, muchos de los cuales permanecen, sin duda, in situ. La excavación realizada en tiempos de la última República por D. Alejandro Ferrant permitió descubrir los muros del panteón real de Alfonso VI, aunque entonces no fuera identificado como tal, y puso de manifiesto la posibilidad de sacar a la luz estructuras prerrománicas y románicas de enorme interés. Las tareas de limpieza llevadas a cabo en el ábside Norte en el año 2000, permiten observar la labor de relleno realizada por el padre Echano con el fin de igualar la cota de suelo en la calle y en el interior de la iglesia, en la zona que había sido cabecera y pasaría a convertirse, mediante la reforma prevista en su proyecto, en pies del templo y lugar de acceso al mismo desde el exterior. Ello confirma nuestra anterior sospecha de que, bajo la gruesa capa de tierra colocada en la remodelación del siglo XIX y la que se ha ido sedimentando sobre ella con el paso del tiempo, puede encontrarse no solo la cimentación, sino también el arranque de todas las estructuras templarias de soporte.

Por otro lado, junto a los cantos rodados y la tierra, se han utilizado como material de relleno sillares y otros elementos pétreos desechados del edificio medieval, que podrían ser recuperados si se realizase un trabajo de excavación sistemática. En 1991, al hacer una cata junto al arco de San Benito, apareció la estatua gótica de San Juan, actualmente expuesta en la iglesia de San Tirso ${ }^{15}$. De la excavación realizada en una pequeña área, correspondiente a poco más que el tramo recto del ábside Norte, se ha

-

15 M. V. Herráez y M. D. Teijeira, "Los siglos del gótico", en Esplendor y decadencia de un monasterio medieval..., pp. 154-155 y 161, láms. 108-109. 
extraído un conjunto de piedras talladas que permanecen amontonadas en un rincón del patio de la Casa-cuartel; entre ellas se distinguen tambores pertenecientes a diversos fustes, basas e incluso un pequeño capitel de esquina precedentes de alguna de las ventanas del templo (fig. 1). Los dibujos realizados por Redondo a finales del siglo XIX, cuando aún se mantenía en pie el muro Sur de la iglesia, muestran la similitud de las piezas exhumadas con las que componían alguno de los vanos (fig. 2). Su hallazgo nos pone en alerta sobre el número de elementos artísticos que se encuentran soterrados y podrían aún recuperarse.

\section{LA CABECERA DE LA IGLESIA ABACIAL}

Durante la segunda década del siglo XIX, como ya ha quedado dicho más arriba, el padre Echano proyectó una drástica reforma del templo monástico que afectó a la orientación del presbiterio y supuso la mutilación de los ábsides de la cabecera románica. De la estructura medieval únicamente se han conservado el tramo recto y el arranque semicircular de la capilla septentrional, hasta la altura del arco de triunfo, así como escasos testimonios de la embocadura de los otros dos ábsides.

A partir de los restos conservados se ha podido reconstruir la planta de la cabecera, compuesta por tres capillas poco profundas y de gran elevación ${ }^{16}$. La relación de la longitud del tramo recto con la luz del arco de triunfo, en la del Norte, es 1:3, proporción que se ha aplicado para trazar el ábside central (figs. 3 y 4).

Por lo que respecta a la escultura, los capiteles en que apea el único arco toral conservado manifiestan un fuerte carácter monumental, sin salirse del uso exclusivo de acantos y volutas. Los tallistas buscaron formas rotundas, sin concesiones a pequeños detalles o a prolijas formas vegetales o geométricas (figs. 5 y 6).

Tanto la planimetría de esta cabecera como sus elementos decorativos conducen a una datación próxima a $1100^{17}$. El escueto trabajo de limpieza y desescombro realizado en el ábside Norte ha rebajado la cota del pavimento 1'37 m.

\footnotetext{
${ }^{16}$ La clave del arco toral de la capilla del evangelio se encuentra a $9 \mathrm{~m}$. de altura.

17 Todos estos aspectos están más ampliamente desarrollados en M. V. HERRÁEZ ET ALII, "La renovación del monasterio en el reinado de Alfonso VI", en Esplendor y decadencia..., pp. 62-72.
}

y ha dejado al descubierto un zócalo de cantería románica realizado con sillería regular y en forma de banco, que recorre perimetralmente el interior de la capilla. En el extremo de los muros dicho banco configura un plinto circular en el que apean los soportes del arco de triunfo. El borde superior del basamento se ha decorado con una moldura ajedrezada similar a la que realza la línea de imposta sobre la que descansa la cubierta. Desgraciadamente no se han destapado las basas de las columnas, recubiertas con estuco en las reformas decimonónicas. (fig. 7)

La presencia de estos elementos permite enriquecer la planta del monasterio, tal y como se había trazado hasta el momento. Las estructuras arquitectónicas, que se definen ahora con más precisión en el ruinoso edificio, confirman la catalogación que anteriormente hicimos de la cabecera del templo abacial como una construcción relacionada con otras iglesias erigidas entre 1080 y $1120^{18}$. El románico que surgió en el ámbito castellano-leonés a la sombra de la reforma litúrgica impulsada por la monarquía y apoyada en los monjes cluniacenses, presenta, en los casos más significativos, unas características similares. Sirvan de ejemplo las iglesias de los monasterios benedictinos de Carrión de los Condes, San Isidoro de Dueñas y San Pedro de Cardeña o el templo de San Martín de Frómista ${ }^{19}$. Tanto el zócalo sobresaliente como los plintos circulares son elementos que se repiten en la cabecera de diversos templos situados en un entorno geográfico y cronológico próximo. Se pueden apreciar en la basílica de San Isidoro, que sirvió como modelo para la iglesia de Nuestra Señora del Mercado de León, el templo sahagunino de San Tirso, disfrazado por las restauraciones de principios del siglo $\mathrm{XX}$, y el del monasterio de San Pedro de las Dueñas, filial de San Facundo, comenzado en el primer tercio del siglo $\mathrm{XII}^{20}$ (fig. 8). En relación con

\footnotetext{
${ }^{18}$ M. V. HERRÁEz ET ALII, "La renovación del monasterio en el reinado de Alfonso VI", en Esplendor y decadencia..., pp. 62-72.

${ }^{19}$ La problemática de la introducción de nuevos modelos arquitectónicos en relación con la renovación monástica del siglo XI en los reinos de Castilla y León, como ya hemos comentado en una nota anterior, ha sido revisada por J. L. SENRA GABRIEL y GALÁN, "Aproximación a los espacios litúrgico-funerarios en Castilla y León: pórticos y galileas", Gesta, vol. XXXVI/2, 1997, pp. 122-144, y “Ángeles en Castilla: reflexiones...”, pp. 261-174, quien recoge la bibliografía anterior.

${ }^{20}$ En la excavación del Panteón de Alfonso VI, construido a partir de 1080 a los pies del templo abacial, también
} 
estos ejemplos, y acorde a la cronología establecida, los machones que separan la capilla mayor de los ábsides laterales debieron presentar una configuración cuadrangular con columnas adosadas en los tres frentes. La estructura acodillada más compleja que se refleja en los planos levantados hasta el momento, es la respuesta lógica a los nervios de la cubierta del crucero, cuyos arranques aún pueden observarse. Sin embargo, como veremos más abajo, ésta fue levantada en la segunda mitad del siglo XII, fecha en la que pudieron reformarse los soportes con el fin de adecuarse a la crucería.

El transepto de la iglesia monástica no responde a los mismos presupuestos estilísticos que la cabecera. Como ya habíamos señalado en nuestro anterior trabajo, se relaciona con modelos castellanos y leoneses erigidos durante la segunda mitad del siglo XII ${ }^{21}$. En efecto, el conjunto de elementos decorativos que utilizaron los escultores en las molduras impostadas, el dibujo de los cimacios y el diseño de las basas resuelto por medio de un prolijo y preciosista tallado, conducen a una datación dentro de la segunda mitad de la duodécima centuria. Características similares se aprecian en el trasdós de la portada de la iglesia del monasterio de Gradefes, comenzado en 1177 , o en detalles decorativos del monasterio de Sandoval, cuya fábrica debe situarse en el último tercio del siglo XII. En resumen, el conjunto de formas que ornamentan el transepto, como la configuración de las ventanas, la composición de las columnas y de los capiteles y el emplazamiento angular de mascarones, nos llevan a ese marco cronológi$\operatorname{co}^{22}$ (fig. 9).

Está claro, por tanto, que la cabecera del templo corresponde a un periodo constructivo inicial, previo al del transepto, y se puede adscribir al reinado de Alfonso VI. Únicamente queda despejar la cuestión, planteada por el doctor Senra, de la posible existencia de una cabecera benedictina con cinco ábsides en lugar

se pudo apreciar con claridad la existencia de un banco perimetral que quedó reflejado en la planta levantada por don Alejandro Ferrant (M. GómEZ MORENO, El arte románico. Esquema de un libro, Madrid, 1934, p. 158).

${ }^{21} \mathrm{M}$. V. HERRÁEZ ET ALII, "La premiosa construcción de un edificio románico", en Esplendor y decadencia..., pp. 93-101.

22 El estudio más pormenorizado de estos materiales escultóricos puede verse en M. V. HERRÁEZ ET ALII, "La premiosa construcción..." en Esplendor y decadencia..., pp. 99-101. de tres ${ }^{23}$. Probablemente, el diseño de la planta dibujada por Melquiades Ranilla, en la que se proyecta un nicho semicircular excavado en el muro oriental del brazo Norte del crucero $^{24}$, le ha inducido a pensar que se trataba de una absidiola y que en el otro lado del transepto pudo haber existido otra simétrica. Dicho edículo no responde a un espacio absidal sino a la construcción, en época incierta, de un nicho que aprovechaba el derrame de una ventana hoy día reabierta (fig. 10). Por otra parte, en los dibujos realizados por el señor Redondo para la Comisión Provincial de Bellas Artes, puede apreciarse que en el muro oriental del brazo Sur no existía exedra alguna (fig. 11). En último extremo, aun cuando en el transepto se hubieran dispuesto espacios a modo de ábsides, dada su cronología, no formarían parte del proyecto de cabecera llevado a cabo en época de Alfonso VI.

\section{LAS MARCAS DE CANTERO}

El estudio de los signos lapidarios y su correcta interpretación ha sido y es, aún hoy, un asunto espinoso, ya que, aunque actualmente se cuenta con importantes corpus de estas señales, el campo de su investigación no está ni mucho menos cerrado ${ }^{25}$.

El valor de estas marcas a la hora de ser aplicadas a la lectura de una obra arquitectónica es cuanto menos controvertido, pero siempre pueden ayudar al mejor conocimiento de la

23 J. L. SENRA Gabriel y Galán, “Ángeles en Castilla: reflexiones...", p. 274, da a entender que cabecera y transepto formaban parte de un mismo proyecto constructivo llevado a cabo en el siglo XII y afirma que "la llamada cabecera benedictina tan solo fue adoptada por Sahagún y Silos ya entrado el siglo XII, con cinco ábsides en ambos casos"

${ }^{24}$ M. V. HERRÁEz (COORD.), Esplendor y decadencia ..., fig. 24.

${ }^{25}$ Para el estado de la cuestión véase, N. REVEYRON, "Marques lapidaires; The State of the Question", Gesta, XLII/2, 2003, pp.161-171, donde aparece una cuidada selección bibliográfica. Para la España medieval y el ámbito leonés, en particular, son de gran utilidad los siguientes trabajos, J. A. FERrer Benemeli, Signos lapidarios en el Románico y Gótico español, Zaragoza, 1975; J. L. PUENTE LÓPEZ Y J. M. SuÁREZ DE PAZ, "Marcas de cantero en la torre y panteón de abades del monasterio de San Miguel de Escalada", Tierras de León, 51, 1983, pp. 71-83; T. MARTIN, "Reading the walls: Mason'marks and the archaeology of architecture at San Isidoro, León", Church. State, Vellum, and Stone.(Essays on Medieval Spain in Honor of John Williams), Leiden-Boston, 2005, pp. 373-412. 
construcción $^{26}$. En este sentido es como vamos a intentar hacer uso de las señales que aparecen sobre los sillares de la zona oriental del templo monástico.

En los muros conservados de los ábsides Norte y Sur y sobre el lienzo oriental del crucero, levantado a partir de la absidiola septentrional, se pueden observar signos lapidarios de distinta índole que parecen corroborar las dos fases de realización de la cabecera de la iglesia (fig. 12).

Así, en la zona inferior de los paramentos, desde el nivel del posible suelo original, alcanzado tras la limpieza del ámbito Norte, hasta el arco de triunfo que cierra en altura la entrada a la capilla, nos encontramos con marcas sencillas y poco variadas, que se limitan a repetir tres letras capitales, la $\mathrm{P}$, con el rasgo curvo alargado por la parte superior, la $\mathrm{E}$ con los tres trazos horizontales idénticos y la $\mathrm{D}$ con terminaciones del rasgo curvo muy marcadas; todas colocadas en distintas posiciones, bien rectas, invertidas o volcadas. Las dimensiones de dichas señales llegan a los $9,5 \mathrm{~cm}$. en el rasgo vertical de la D y la localización de las mismas no es siempre igual respecto a la superficie visible del sillar, parecen no obedecer a pautas de ubicación rígidas; además, las piezas pétreas presentan generalmente un aspecto granuloso en su superficie que no las hace resaltar.

Una $M$ de perfiles curvos también está presente en la zona inferior. A pesar de que puede tratarse de una letra carolina no permite extraer conclusiones ya que aparece sobre un sillar que fue removido y sirvió de refuerzo mural, junto con otras muchas piezas, para los cambios que se dieron en el edificio en el siglo XIX, al ser trasladado el presbiterio hacia el Oeste y cerrar la comunicación entre el brazo del transepto y el resto del templo.

Estos signos lapidarios son muy comunes en las obras románicas; en concreto, en la catedral de Santiago de Compostela están presentes la $\mathrm{D}$ y la $\mathrm{P}^{27}$. En San Isidoro de León, las tres letras, P, D y E, citadas anteriormente, se locali-

\footnotetext{
${ }^{26}$ En la bibliografía recogida en la nota anterior se advierte de los debates que han suscitado los estudios de los signos lapidarios a la hora de ser interpretados, pero también se apunta su utilidad.

27 J. A. FERRER Benemeli, Signos lapidarios en el Románico y Gótico español, Zaragoza, 1975, p. 367.
}

zan en fases sucesivas de la construcción del templo, dependencias palaciegas y torre, por lo tanto, señalan cronologías amplias que se mueven desde fechas en torno a 1100 hasta bien avanzado el siglo $\mathrm{XII}^{28}$. La reutilización del mismo signo lapidario por canteros de distintas generaciones es un hecho comprobado ${ }^{29}$; por ello, es posible encontrar también la $\mathrm{P}$ en Santa María del Mercado de León, en el muro Norte del templo, obra datada en el siglo $\mathrm{XII}^{30}$. Por otra parte, en la cabecera de la iglesia del Monasterio de San Pedro de las Dueñas, muy próximo a Sahagún y relacionado directamente con él desde su fundación, vuelven a aparecer las tres letras citadas ${ }^{31}$.

Parece que el taller de origen de estos signos dio lugar a la formación de una serie de canteros que participaron en tres grandes obras del reino de León activas en torno a 1100, la catedral de Santiago de Compostela, la Colegiata de San Isidoro y el monasterio de Sahagún. Además, su presencia y la de sus sucesores en el trabajo de cantería se advierte en fábricas coetáneas de menor envergadura y en otras de cronología posterior.

El límite topográfico de aparición de los tres signos reseñados es justamente la rosca del arco de triunfo, en cuyas dovelas se ha grabado repetidamente la D. A partir de esa línea, en la zona construida sobre la absidiola septentrional, que formaría parte de los muros orientales del crucero, se pueden ver gran variedad de marcas grabadas; así, a las letras capitales T, N o I, con terminaciones triangulares muy marcadas, se unen modelos de llave con cabeza circular o romboidal, una estrella de cinco puntas, varias cruces de doble travesaño y algunas cabezas de

\section{-}

28 T. MARTIN, "Reading the walls...", especialmente pp. 397-398

29 J. A. FERRER BENEMELI, Signos lapidarios en el Románico y Gótico español, p. 323.

30 ; M. Gómez MoRENO, Catálogo monumental de España. Provincia de León, Madrid, 1925, pp. 215-217; L. MENÉndez PidAL, "La iglesia de Santa María del Mercado de León", Academia. Boletín de la Real Academia de Bellas Artes de San Fernando, no 31, 1970, pp. 67-68; A. ÁlvAREZ ÁlvareZ, "Origen y vicisitudes del templo leonés del Mercado", Tierras de León, n 32-33, XVIII, 1978, p. 37.

${ }^{31}$ Para San Pedro de las Dueñas, cuya cabecera se construyó posiblemente dentro del primer tercio del siglo XII, véase la bibliografía especificada en el artículo correspondiente, realizado por J. L. SENRA GABRIEL Y GALÁN, de la Enciclopedia del Románico de Castilla y León. León, Aguilar de Campoo, 2002, pp. 727-738. 
pájaro, de cuello largo o corto, que en uno de los casos se duplican y afrontan en un mismo sillar. Además, la letra I puede desarrollarse teniendo adosados a su derecha tres rasgos paralelos en horizontal y también se observan otros signos en voluta o una especie de $\mathrm{H}$ minúscula con el rasgo superior tumbado.

Estas marcas tienen medidas desiguales, con longitudes que alcanzan los $12,5 \mathrm{~cm}$. en una de las llaves, y generalmente se disponen de modo aleatorio, de nuevo, sobre los sillares. Los signos lapidarios se realizaron, posiblemente, con un punzón no muy grueso y tienen la suficiente profundidad para que sean perfectamente visibles en la actualidad. El grado de definición y perfección de las líneas los diferencia de las marcas localizadas en la cabecera.

Además de los restos encontrados in situ, tenemos que añadir las marcas de cantero que aparecen en los dibujos realizados por el señor Redondo, custodiados en la Biblioteca Provincial de León. En dichas representaciones, realizadas antes de la destrucción de parte del transepto y paramentos del mediodía del templo, se han reseñado un buen número de signos, entre ellos ciertas letras capitales como F, E, M, A, U y se repiten la voluta, T, $\mathrm{N}$ e I. Además hay una especie de ángulo recto que semeja una $\mathrm{L}$, una cruz sencilla y un asterisco. A ellos se unen dos cabezas de pájaro con los cuellos entrelazados como los que existen en la torre escalera del crucero Norte.

El abundante repertorio de marcas del transepto hace pensar en la participación de una mano de obra más numerosa y, sobre todo, la relación de ciertos signos más complejos con otros edificios medievales de la región, perfectamente datados, nos ayuda a afianzar la hipótesis de la continuación de la obra del templo monástico en la segunda mitad del siglo XII. Nos referimos al hallazgo de los mismos tipos de señales en las fases más tardías de San Isidoro de León y en los monasterios cister de Santa María de Gradefes o Santa María de Sandoval, entre otros. Por ejemplo, las cabezas de pájaro de cuello corto con ojo bien delimitado y pico curvo se encuentran en los muros de la sala capitular, en la panda este del claustro y en el piso superior de la torre de San Isidoro, trabajos que se llevaron a cabo a partir de $1150^{32}$. Ade-

\footnotetext{
32 T. MARTIN, "Reading the walls..., pp. 391 y 399.
}

más, aparece esta imagen en los muros del llamado panteón de abades de San Miguel de Escalada y en la cabecera del templo del monasterio de Santa María de Gradefes, edificio en el que también están presentes las figuras de llave con cabeza romboidal y la estrella de cinco $\operatorname{puntas}^{33}$.

Por otra parte, la cabeza de ave de cuello largo así como la I de trazo profundo y terminaciones triangulares se encuentran en el templo del monasterio de Santa María de Sandoval, construcción que se comenzó a edificar a finales del siglo XII ${ }^{34}$.

Respecto a otros aspectos relacionados con la labor de cantería, cabe señalar que la fábrica está realizada con una buena y bien escuadrada sillería, si bien se aprecian diferencias entre las dos fases de construcción ya señaladas. Los sillares del muro oriental del transepto son ligeramente más pequeños que los de los ábsides y están trabajados con un instrumento que deja como huella líneas paralelas, oblicuas a las aristas del sillar, observables en toda la cara externa. Sin embargo, en la cabecera, las superficies se presentan lisas y con el granulado propio de la caliza.

Es bien sabido que los muros de las iglesias medievales no se concebían para dejar la

33 J. L. Puente López y J. M. SuÁrez de PAZ, "Marcas de cantero en la torre y panteón de abades..., pp. 80 y 85 ; T. MARTIN, "Reading the walls..., pp. 391. Respecto a la construcción románica de San Miguel de Escalada, se ha mantenido la datación propuesta por don Manuel Gómez Moreno de finales del siglo XI (M. GómEz Moreno, Catálogo monumental de España. Provincia de León, Madrid, 1925, p. 108; M. V. HERRÁEZ ORTEGA, "Arte románico en la cuenca del río Esla (I). Arquitectura", Tierras de León, $\mathrm{n}^{\circ}$ 48 (1982), pp. 153-175; A. M. MARTínez TEJERA, "San Miguel de Escalada", en Enciclopedia del románico en Castilla y León. León, Salamanca, 2002, pp. 619-628, esp. 625, y El templo del "monasterium" de San Miguel de Escalada, Madrid, 2005, pp. 144-147). Sin embargo, una observación detenida de la estructura arquitectónica y de la talla de los elementos decorativos conduce a retrasar la cronología hasta bien avanzada la centuria siguiente. Este análisis queda, además, reforzado por la forma de trabajo de la cantería y los signos lapidarios conservados. El templo del monasterio de Gradefes está en construcción a partir del último tercio del siglo XII, véase, E. FERnÁNDEZ, C. CoSMEN Y M. V. HERRÁEZ, El arte cisterciense en León, León 1988, pp. 71-85 y M. MARTIN, Marcas de Cantero. Monasterio cisterciense Santa María de Gradefes, León, 1994, fotografías sin numerar.

${ }^{34}$ Véanse, C. CASADO y A. CEA, Los Monasterios de Santa María de Carrizo y Santa María de Sandoval, León, 1986, pp. 69-76 y E. FERnÁndeZ, C. COSMEN Y M. V. HERRÁEZ, El arte cisterciense en León, pp. 71-86 y 105-117 
piedra vista. En el caso del transepto de Domnos Sanctos, la intención de revocarlo es bien patente. Por un lado, la disposición de los sillares con las huellas del corte en distintas direcciones resulta poco estético; por otro, en el plinto de uno de los soportes de la ventana situada sobre el arco toral de la capilla del evangelio, quedan restos del pautado preparatorio para su decoración, lo que, de nuevo, implica que el muro iba a ser revestido inmediatamente. Además, el rayado de las piezas pétreas favorecería la adhesión de la pintura.

El uso de esta herramienta con la que se escuadraron los sillares de Sahagún en la segunda mitad del siglo XII se percibe también en las fases avanzadas de San Isidoro, en Santa María de Sandoval, en la parte románica de San Miguel de Escalada y en Santa María de Gradefes, en donde la superficie de los sillares presenta un rayado similar ${ }^{35}$.

Por todo lo expuesto, podemos concluir que durante un amplio periodo de tiempo, prác- prácticamente los últimos cinquenta años de la duodécima centuria, las grandes obras arquitectónicas que estaban en curso en la diócesis de León tuvieron mucho en común. Parece evidente que hubo una conexión muy fuerte entre los grupos de tallistas que cortaban y preparaban los sillares para las fábricas de todos los edificios que hemos citado, a pesar de pertenecer a comunidades muy distintas, con intereses y directrices estéticas variadas. No obstante, la necesidad de encontrar obreros cualificados parece soslayar estas diversidades. Así, las casas benedictinas de Sahagún y San Pedro de las Dueñas, las cistercienses de Santa María de Gradefes y Santa María de Sandoval, los canónigos de San Miguel de Escalada y los de San Isidoro de León, armonizaron sus intereses a la hora de utilizar esa mano de obra que realizaría campañas sucesivas $o$ intercaladas en unas $u$ otras fábricas, produciendo, como ya habíamos escrito hace muchos años, una evidente uniformidad artística $^{36}$.
35 Véanse, como ejemplos, M. MARTin, Marcas de Cantero. Monasterio cisterciense Santa María de Gradefes, León, 1994, fotografías sin numerar, y J. L. PUENTE LÓPEZ Y J. M. SUÁREZ DE PAZ, "Marcas de cantero en la torre y panteón de abades del monasterio de San Miguel de Escalada", Tierras de León, 51, 1983, pp. 71-83, fotografías no 6 y 7.
${ }^{36}$ E. FERNÁNDEZ, C. COSMEN Y M. V. HERRÁEZ, El arte cisterciense en León, pp. 38-42. 


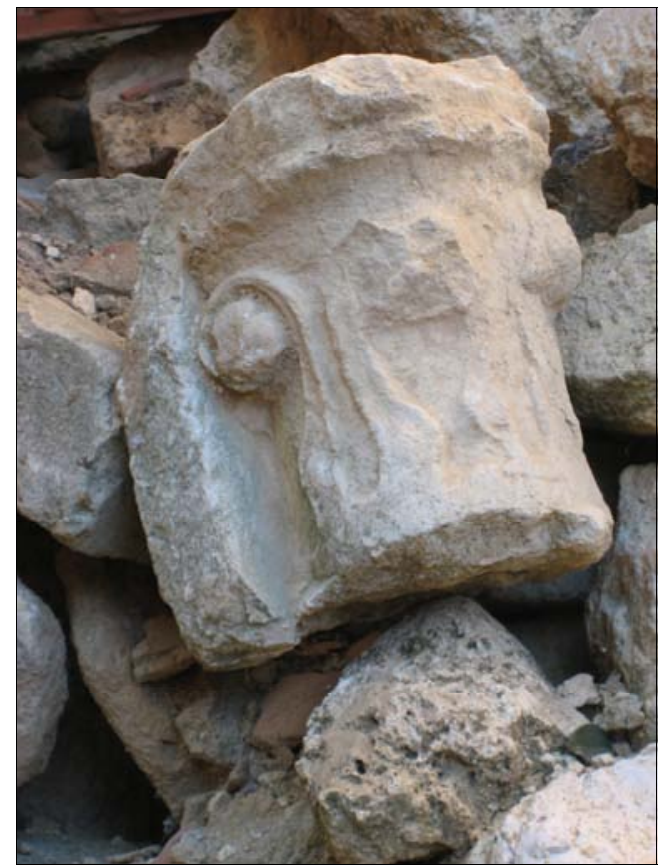

- Fig. 1. Monasterio de Sahagún. Capitel exhumado.

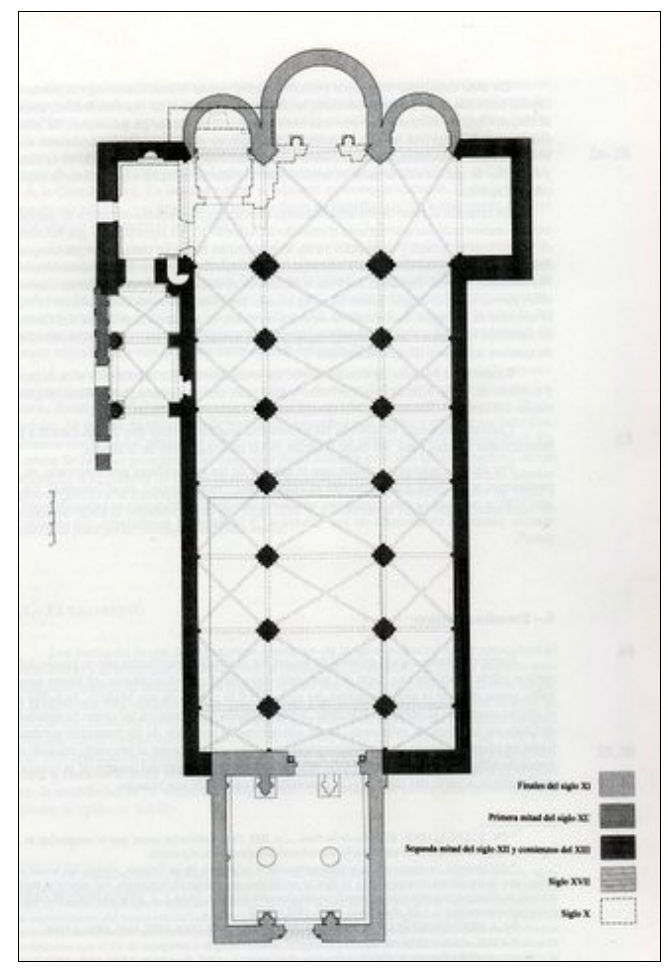

- Fig. 3. Planta del templo y panteón del monasterio de Sahagún (M. V. HerráEz, Coord., Esplendor y Decadencia, p. 91).

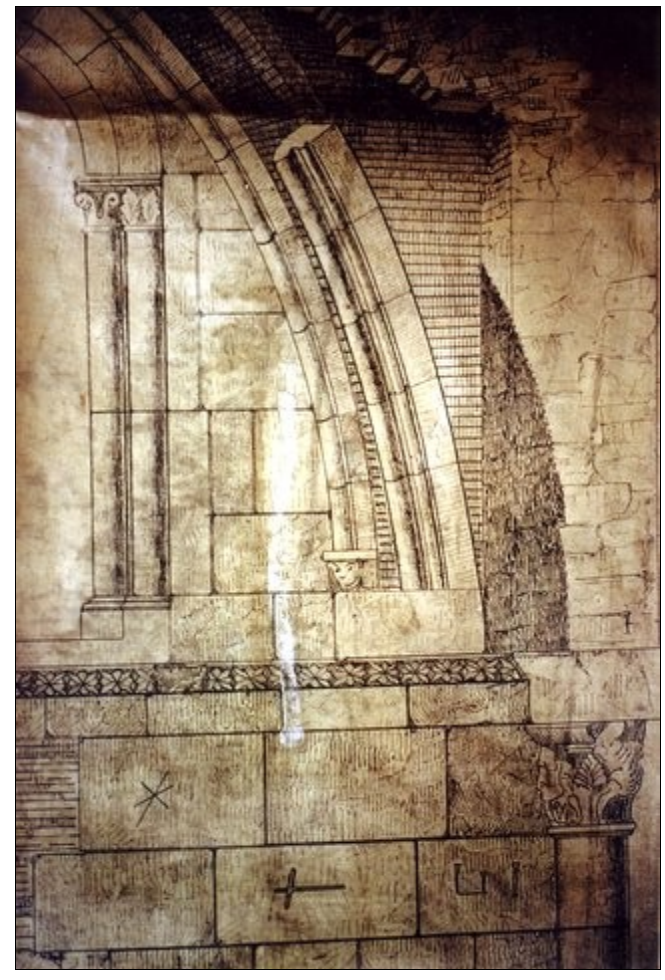

- Fig. 2. Dibujo de una ventana del monasterio de Sahagún Inocencio Redondo).

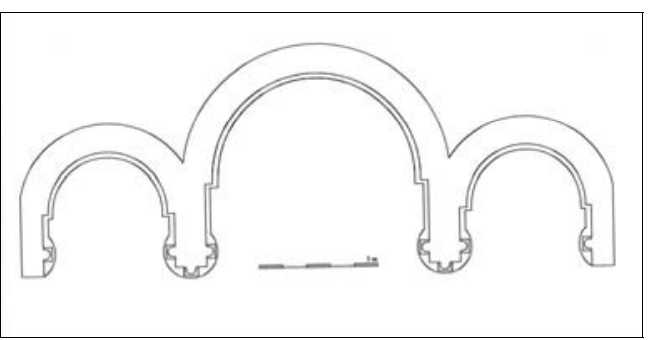

- Fig. 4. Monasterio de Sahagún. Nueva planimetría de la cabecera. 


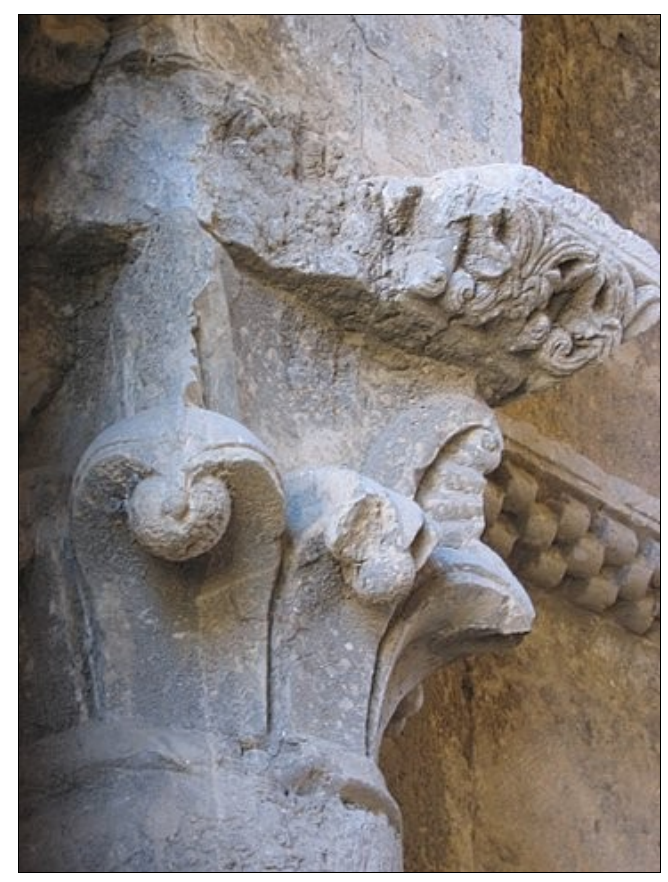

- Fig. 5. Monasterio de Sahagún. Capitel izquierdo de la capilla del evangelio.

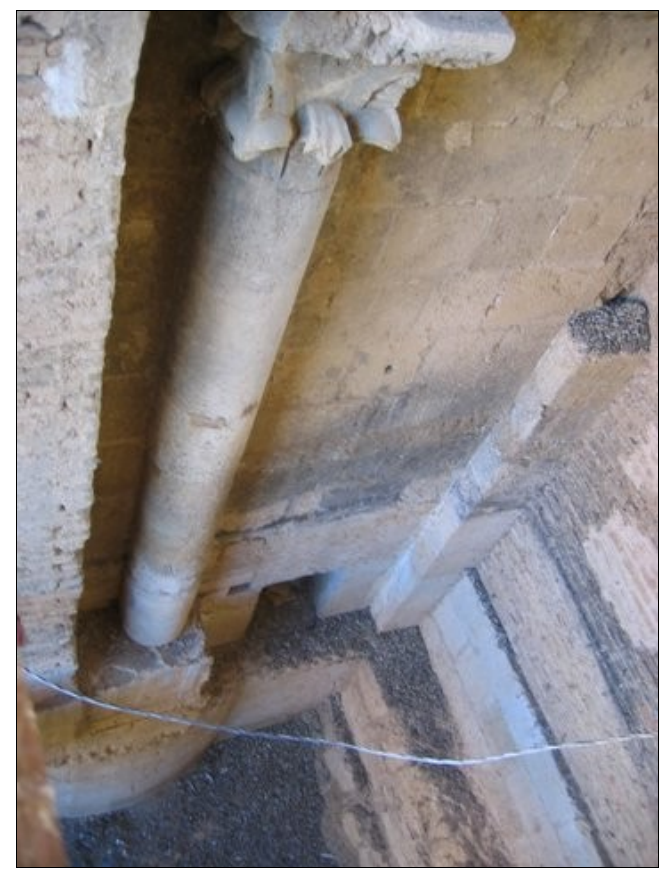

- Fig. 7. Monasterio de Sahagún. Muro Norte de la capilla del evangelio.

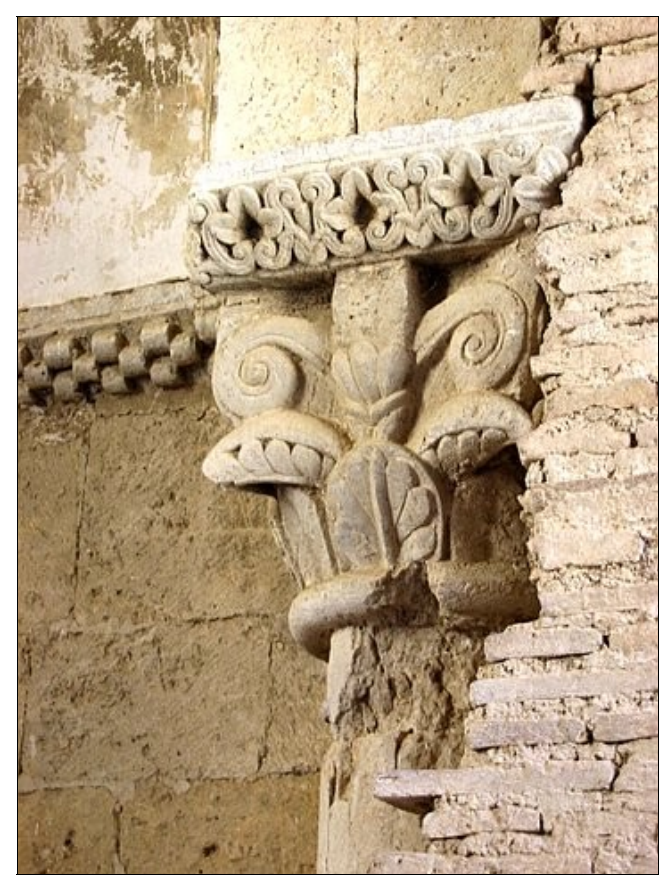

- Fig. 6. Monasterio de Sahagún. Capitel derecho de la capilla del evangelio. 


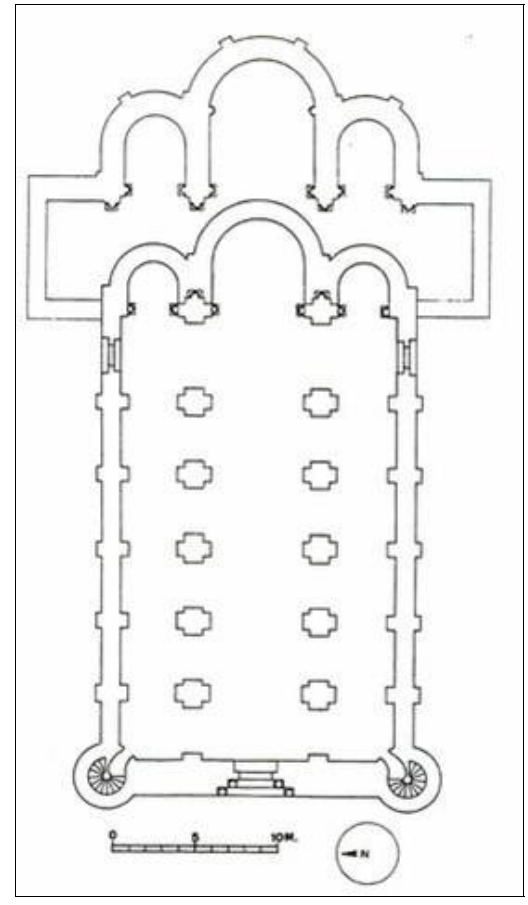

- Fig. 8a. San Isidoro de Dueñas. Planta con dos fases de const. (según Senra).

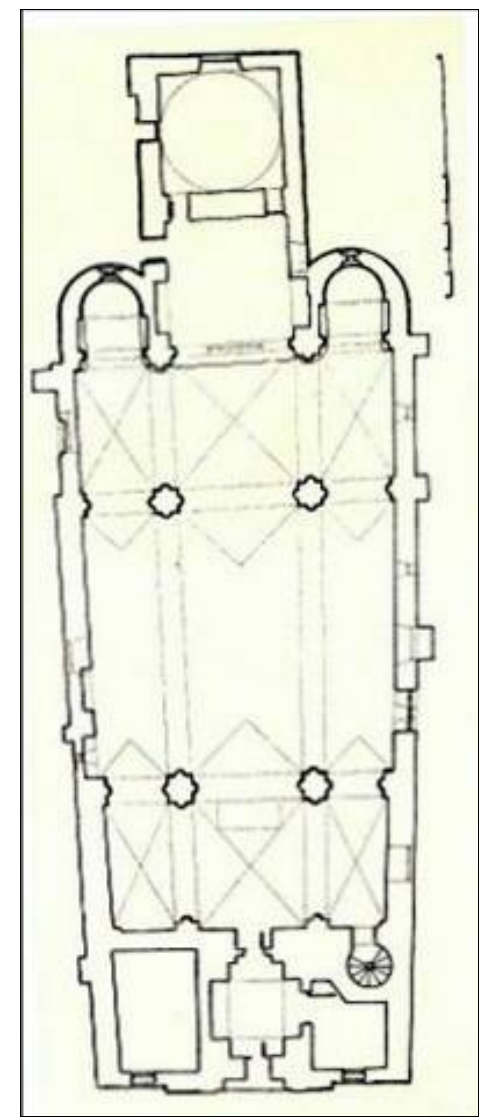

- Fig. 8c. Ntra. Sra. Del Mercado de León. Planta.

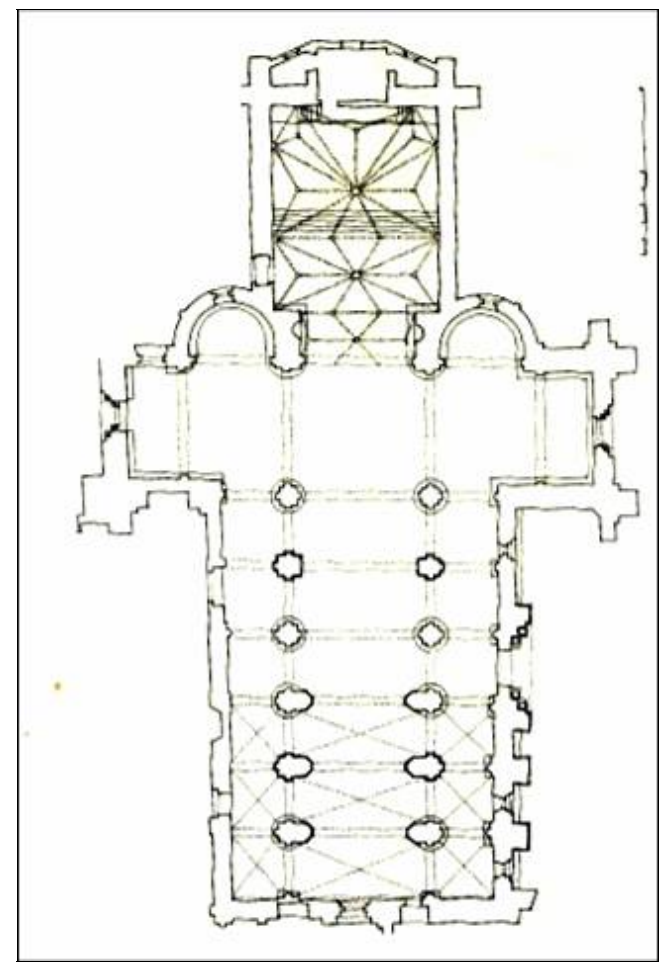

- Fig. 8b. San Isidoro de León. Planta.

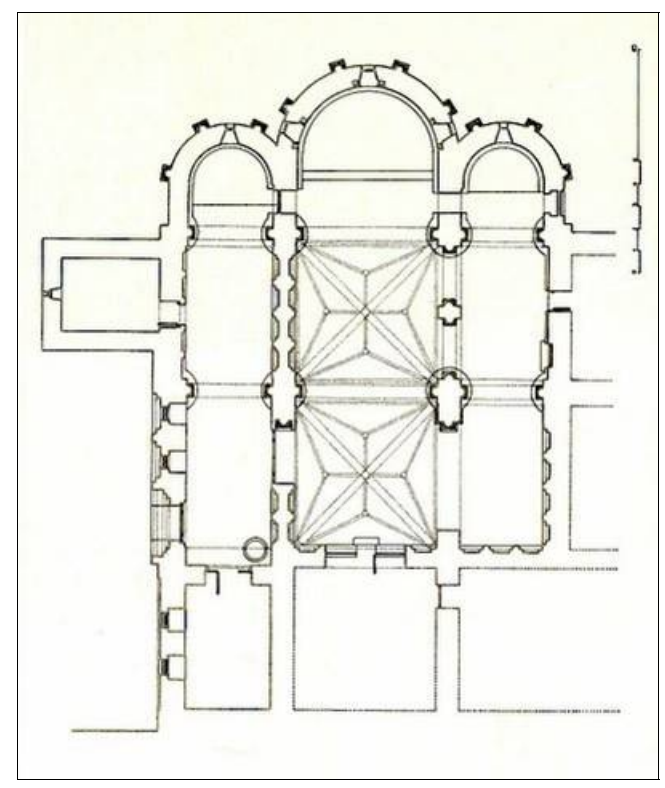

- Fig. 8d. San Pedro de las Dueñas. Planta. 


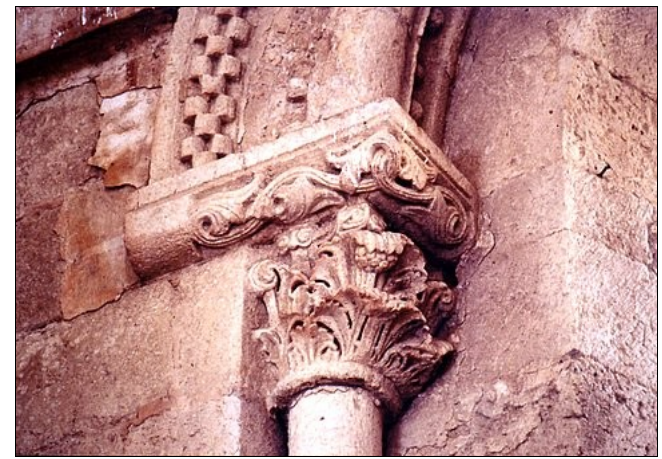

- Fig. 9. Monasterio de Sahagún. Capitel de la ventana del crucero del muro oriental del brazo N. del crucero..

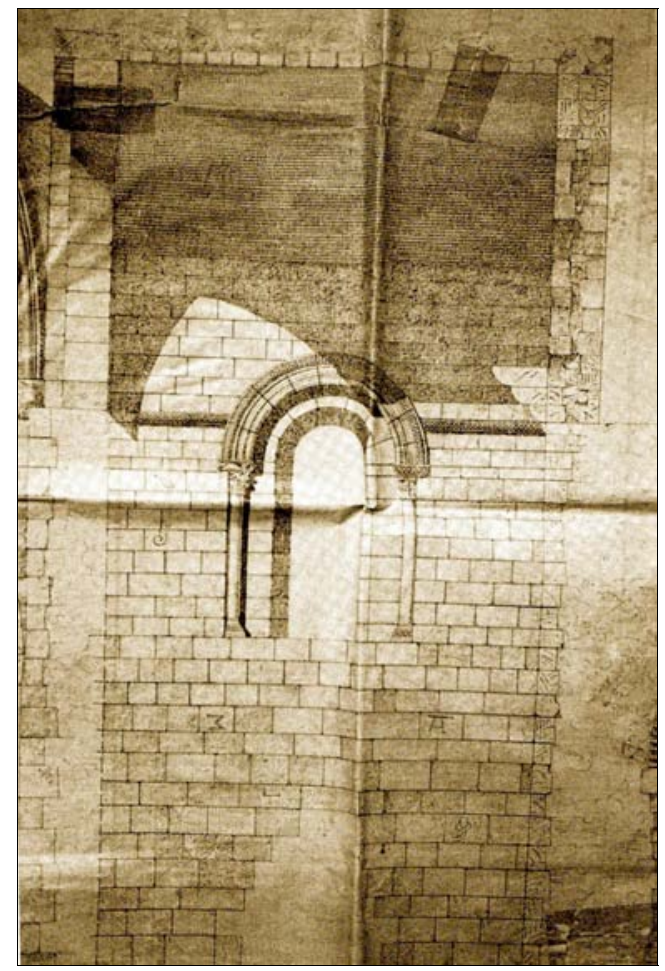

- Fig. 11. Monasterio de Sahagún. Dibujo del muro oriental del brazo S. del crucero.

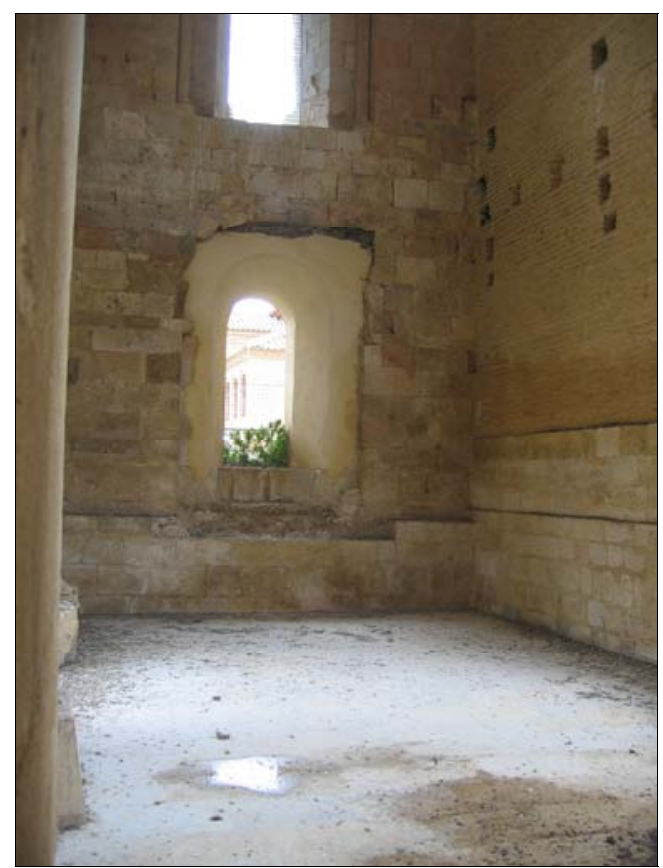

- Fig. 10. Monasterio de Sahagún. Muro oriental del brazo del transepto E.Norte.

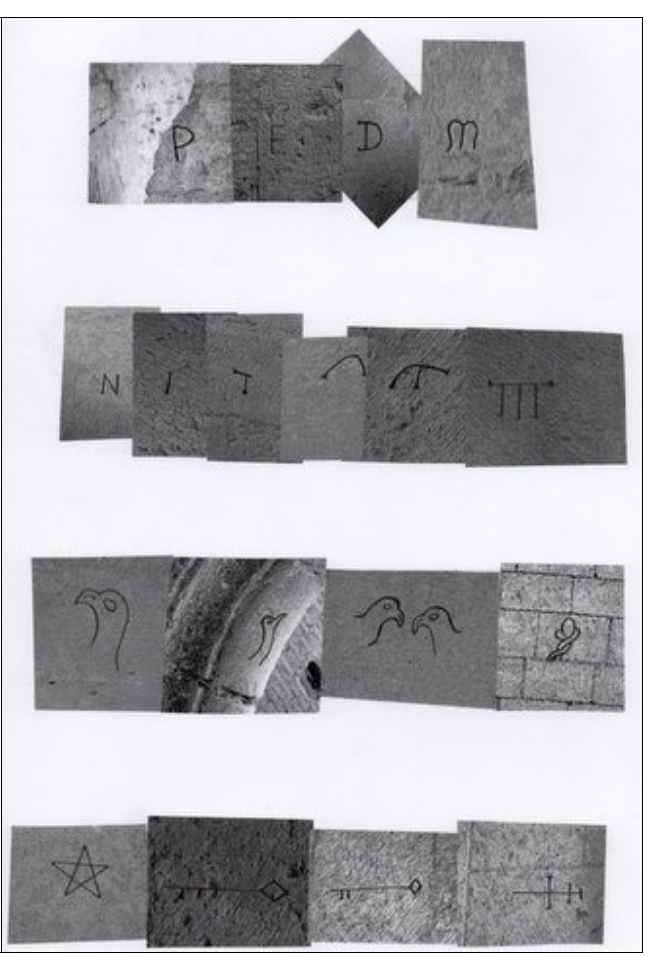

- Fig. 12. Marcas de cantero. 